\title{
Growth effects and assimilation of organic acids in chemostat and batch cultures of Acidithiobacillus caldus
}

\author{
John E. Aston - William A. Apel • Brady D. Lee • \\ Brent M. Peyton
}

Received: 30 November 2009/Accepted: 3 May 2010/Published online: 18 May 2010

(C) Springer Science+Business Media B.V. 2010

\begin{abstract}
The ability of Acidithiobacillus caldus to grow aerobically using pyruvate, acetate, citrate, 2-ketoglutarate, succinate, and malate as either an electron donor and carbon source (heterotrophic growth), or as a carbon source when potassium tetrathionate was added as an electron donor (mixotrophic growth), was tested in chemostat cultures. Under both heterotrophic and mixotrophic conditions, organic acids were added to a sub-lethal concentration $(50 \mu \mathrm{M})$. Under mixotrophic conditions, potassium tetrathionate was added to an excess concentration $(10 \mathrm{mM})$. No cell growth was observed under heterotrophic conditions; however, effluent cell concentrations increased over threefold when pyruvate was coupled with potassium tetrathionate. Under these conditions, the effluent pyruvate concentration was reduced to below the detection limit $(2 \mu \mathrm{M})$, and oxygen consumption increased by approximately $100 \%$. Although pyruvate provided a carbon source in these experiments, ambient carbon dioxide was also available to the cells. To test whether At. caldus could grow mixotrophically using pyruvate as a sole carbon source and potassium tetrathionate as an electron donor, cells were batch cultured in a medium free of dissolved inorganic carbon, and with no carbon dioxide in the headspace. These experiments showed that At. caldus was able to convert between $65 \pm 8$ and $82 \pm 15 \%$ of the pyruvate carbon to cellular biomass, depending on the
\end{abstract}

\footnotetext{
J. E. Aston · B. M. Peyton $(\bowtie)$

Department of Chemical and Biological Engineering, Montana

State University, 306 Cobleigh Hall, PO Box 173920, Bozeman,

MT 59717-3920, USA

e-mail: Bpeyton@coe.montana.edu

W. A. Apel · B. D. Lee

Biological Systems Department, Idaho National Laboratory,

2025 Fremont Avenue, Idaho Falls, ID 83415, USA
}

initial pyruvate concentrations. This work is the first to identify a defined organic-carbon source, other than glucose, that At. caldus can assimilate. This has important implications, as mixotrophic and heterotrophic activity has been shown to increase mineral leaching in acidic systems.

Keywords Acidithiobacillus - Biomining - Chemostat . Organics

\section{Introduction}

Compared to the more commonly studied Acidithiobacillus thiooxidans (Waksman and Joffe 1922) and Acidithiobacillus ferrooxidans (Temple and Colmer 1951), relatively little is known about At. caldus. As with all acidithiobacilli, At. caldus thrives at low pH (optimum $\mathrm{pH}$ is 2.0-2.5); however, unlike other acidithiobacilli, At. caldus grows well at moderately high temperatures, with optimum growth at $45^{\circ} \mathrm{C}$ (Hallberg and Lindstrom 1994). At. caldus oxidizes sulfur and reduced sulfur compounds for energy, and can fix carbon dioxide as a sole carbon source (Dopson et al. 2002; Hallberg and Lindstrom 1994, 1996). At. caldus has also been reported to grow mixotrophically using tetrathionate as an electron donor and either glucose or yeast extract as a carbon source (Hallberg and Lindstrom 1994). The conditions at which At. caldus thrives, coupled with its ability to oxidize reduced sulfur compounds, make it important in many acid-mine systems around the world (Rawlings 2002; Okibe et al. 2003), where it stimulates mineral sulfide leaching (Dopson and Lindstrom 1999; Edwards et al. 2000; Fu et al. 2008; McGuire et al. 2001; Zhou et al. 2007).

There are many considerations affecting the bioleaching of metals in acid-mine environments, one of these is the 
presence and concentration of organic acids (Burckhard et al. 1995; Marchland and Silverstein 2003; Olson et al. 2003; Gu and Wong 2004, 2007). The toxicity of lowmolecular weight organic acids to microorganisms is well documented. These effects increase at low $\mathrm{pH}$ where weak acids are highly protonated and can more easily diffuse across the cell membrane, weakening the proton motive force (Ingledew and Poole 1982). In addition, Tuttle et al. (1977) observed a loss of integrity in the cellular envelope of acidophilic chemolithotrophs when exposed to inhibitory concentrations of organic acids. Because of these effects, heterotrophic or mixotrophic activity in carbonlimited bioleaching systems can improve leaching efficiency by reducing organic acid concentrations (Marchland and Silverstein 2003; Olson et al. 2003; Gu and Wong 2004, 2007).

In the present study, the ability of At. caldus to use pyruvate, acetate, citrate, 2-ketoglutarate, succinate, and malate as an electron donor and carbon source (heterotrophic growth) and as a carbon source coupled with the inorganic electron donor, potassium tetrathionate (mixotrophic growth), was studied in chemostat and batch cultures. These organic acids were chosen because of their presence in the spent medium of acidophilic sulfuroxidizing autotrophs (Schnaitman and Lundgren 1965), and their toxicity to acidithiobacilli (Aston et al. 2009; Borischewski 1967; Matin 1978).

\section{Materials and methods}

\section{Media preparation}

At. caldus strain BC13 (ATCC 51757) was grown in the basal salts medium and trace elements used by Hallberg and Lindstrom (1994). To prepare the medium, nanopure water (17.4 M $\Omega$ ) was added to the salts to volume, and the medium was autoclaved for $15 \mathrm{~min}$ at $121^{\circ} \mathrm{C}$ and $152 \mathrm{kPa}$ gauge. After the medium cooled to room temperature, $1 \mathrm{ml} \mathrm{l}^{-1}$ of the filter sterilized $(0.2 \mu \mathrm{m})$ trace element solution was added, and the $\mathrm{pH}$ was adjusted to $2.5 \mathrm{using}$ $6 \mathrm{~N}$ sulfuric acid. Cells preserved at $4^{\circ} \mathrm{C}$ in nanopure water (17.4 M $\Omega$ ) with the $\mathrm{pH}$ adjusted to 3.0 using $6 \mathrm{~N}$ sulfuric acid, provided the initial inoculum. An organic acid stock solution was prepared the same day and filter sterilized $(0.2 \mu \mathrm{m})$ into the medium to give the desired final organic acid concentration.

\section{Chemostat culturing}

Pronk et al. (1989) showed Thiobacillus acidophilus could oxidize pyruvate in chemostat cultures, but not in batch cultures. Because of this, chemostat cultures were used in the initial experiments discussed here. Prior to inoculation into a continuous-flow system, At. caldus cells were grown in $500-\mathrm{ml}$ serum bottles ( $350 \mathrm{ml}$ medium volume) fitted with butyl-rubber stoppers. Filter sterilized $(0.2 \mu \mathrm{m})$ potassium tetrathionate was added to a concentration of $10 \mathrm{mM}$ as the electron donor, and carbon dioxide provided the sole carbon source. The serum bottles were placed in a temperature controlled incubator at $45^{\circ} \mathrm{C}$, and shaken at 150 rotations per min (rpm). During the late-log growth phase, pyruvate, acetate, citrate, 2-ketoglutarate, succinate, or malate was added to a concentration of $10 \mu \mathrm{M}$ to preadapt the cells to each organic acid. Cells were harvested using centrifugation $(7,000 \mathrm{~g})$ during the late-exponential growth phase, and were washed three times in $\mathrm{pH} 3.0$ nanopure water $(17.4 \mathrm{M} \Omega)$ to minimize substrate transfer. An aliquot of cells that provided between $5.0 \times 10^{7}$ and $5.5 \times 10^{7}$ cells $\mathrm{ml}^{-1}$ was inoculated into $500 \mathrm{ml}$ of fresh growth medium in a continuous-flow SIXFORS reactor (ATR, Columbia, MD, USA), maintained at $45^{\circ} \mathrm{C}$, and agitated using a magnetic stir bar rotating at $200 \mathrm{rpm}$.

To test for heterotrophic growth, pyruvate, acetate, citrate, 2-ketoglutarate, succinate, or malate were added to the influent to a sub-lethal concentration of $50 \mu \mathrm{M}$ (Aston et al. 2009). To test for mixotrophic growth, parallel experiments were run, using an influent medium containing $10 \mathrm{mM}$ potassium tetrathionate, in addition to the organic acids, to provide an inorganic electron donor. In either case, the influent was delivered at $5 \mathrm{ml} \mathrm{h}^{-1}$, setting the dilution rate at $0.01 \mathrm{~h}^{-1}$. An adjacent SIXFORS pump removed the effluent, maintaining a constant medium volume in each chemostat.

Cell concentrations were measured by direct counts using a counting chamber (Hausser Scientific, Horsham, PA, USA), and a phase-contrast microscope at $1,000 \times$ (Zeiss, Thornwood, NY, USA). Cultures were monitored until cell concentrations either reached steady-state, or washed out. Effluent samples were then saved at $4^{\circ} \mathrm{C}$ for measurement of organic acid concentrations.

Organic acid measurement

Samples collected for organic acid measurements were concentrated using a CentriVap Concentrator (LABCONCO, Kansas City, MO, USA). Concentrations were measured using capillary electrophoresis (CE) (BioRad 4000, Hercules, CA, USA) against an anion buffer (Agilent, Santa Clara, CA, USA). A capillary cartridge $104 \mathrm{~cm}$ in length, with an inside diameter of $50 \mu \mathrm{m}$, was washed with nanopure water $(17.4 \mathrm{~m} \Omega)$ and the buffer solution between each sample run. Samples were injected at 50 mbar for $6 \mathrm{~s}$, and run positive to negative at $30 \mathrm{kV}$. Absorbance was measured at $350 \mathrm{~nm}$. 
Dissolved oxygen and inorganic carbon measurement

The dissolved oxygen concentrations were measured using an HQ40d dissolved oxygen probe (HACH, Loveland, CO, USA). The probe was calibrated using water at 22 and $45^{\circ} \mathrm{C}$. To measure dissolved inorganic carbon, samples were collected using a $3-\mathrm{ml}$ syringe and filtered $(0.2 \mu \mathrm{m})$ into a 30-ml serum bottle, capped with a butyl-rubber stopper, that had been purged with filter sterilized $(0.2 \mu \mathrm{m})$ ultra-pure nitrogen gas for $5 \mathrm{~min}$ to remove ambient carbon dioxide. A 1-ml syringe was then used to transfer the samples to a carbon analyzer (Dohrmann, St. Cloud, MN, USA). The UV-light apparatus, normally used to cleave organic compounds into dissolved inorganic carbon, was turned off, so that only dissolved inorganic carbon was measured.

Dry-cell weight and carbon composition measurement

It was necessary to measure the carbon composition of At. caldus cells to determine carbon yield on pyruvate during mixotrophic growth. A 50-ml effluent sample from a chemostat culture at steady state was collected and centrifuged. Cells were dried in a Samdri-795 critical point dryer (Tousimis, Rockville, MD), and then placed in an oven at $80^{\circ} \mathrm{C}$ for $48 \mathrm{~h}$. Dry weights were recorded and correlated with direct-cell counts to calculate a specific dry-cell weight. The cell pellet was resuspended in $10 \mathrm{ml}$ of nanopure water $(17.4 \mathrm{~m} \Omega)$ and sonicated for $30 \mathrm{~s}$ using a Branson 1020 sonicator (Danbury, CT, USA). This sample was introduced into the carbon analyzer, with the UV-light apparatus turned on. After the specific dry-cell weight and carbon mass was measured, the percent carbon composition of At. caldus was calculated.

Batch growth with pyruvate as the sole carbon source

Inorganic carbon was removed from the growth medium by sparging $350 \mathrm{ml}$ of heated $\left(80^{\circ} \mathrm{C}\right)$ medium, in a $500-\mathrm{ml}$ serum bottle fitted with a butyl-rubber stopper, with carbon dioxide-free air for $30 \mathrm{~min}$. Because chemostat experiments showed that At. caldus could not use pyruvate as a sole electron donor, potassium tetrathionate was added to a concentration of $10 \mathrm{mM}$ and pyruvate was added to a concentration of $5,10,15$, or $20 \mu \mathrm{M}$. Controls showed the dissolved inorganic carbon concentration in the medium was below the detection limit $(\sim 1 \mu \mathrm{M})$. The medium was then inoculated with At. caldus cells that were pre-adapted to pyruvate. To adapt the cells to pyruvate, cells were harvested during the late-exponential growth phase of a growth cycle, and washed using the methods described earlier. Cells were then re-inoculated into fresh medium, containing the same initial organic acid concentration. This process was repeated a total of three times.

Cell concentrations were measured using direct counts (described earlier) and the specific growth rates were calculated (Eq. 1).

$\mu=\frac{\mathrm{d} C}{C \mathrm{~d} t}$

where $\mu$ is the specific growth rate, $C$ is the cell concentration, and $\mathrm{d} C$ and $\mathrm{d} t$ are the cell concentration and time derivatives, respectively. Samples were collected at the end of the exponential growth phase to measure pyruvate concentrations using the methods described earlier. The growth of these cultures was compared with potassium tetrathionate-free, pyruvate-free, and pyruvate plus carbon dioxide controls.

Growth effects of organic acids in batch cultures

In separate experiments, the toxicity of organic acids was determined at concentrations at and below $50 \mu \mathrm{M}$. At. caldus was grown in $125-\mathrm{ml}$ serum bottles $(75 \mathrm{ml}$ medium volume) fitted with butyl-rubber stoppers. Potassium tetrathionate was added to a concentration of $10 \mathrm{mM}$ as an electron donor. Prior to inoculation, pyruvate, acetate, citrate, 2-ketoglutarate, succinate, or malate was added to a concentration of $5,10,20,30$, or $50 \mu \mathrm{M}$. Ambient carbon dioxide was also available as a carbon source. Cells preserved at $4^{\circ} \mathrm{C}$ in $\mathrm{pH} 3.0$ nanopure water $(17.4 \mathrm{M} \Omega$ ) provided the initial inoculum. The serum bottles were placed in a temperature controlled incubator at $45^{\circ} \mathrm{C}$ and shaken at $150 \mathrm{rpm}$. To calculate specific growth rates, cell concentrations were measured by direct counts. This experiment was repeated in parallel with cultures that had been preadapted to organic acids through subsequent transfers, using the methods described earlier.

$16 \mathrm{~S}$ culture analysis

A polymerase chain reaction (PCR) amplification of the $16 \mathrm{~S}$ gene verified that the cultures were not contaminated. After chemostat cultures had reached steady-state, and after batch cultures had reached late-log phase growth, DNA was extracted using a DNA soil extraction kit (Promega, Madison, WI, USA). The PCR reaction was carried out in an Eppendorf master cycler gradient thermocycler (New York, NY, USA) using $8 \mathrm{~F}$ and $1492 \mathrm{R}$ primers, and a PCR master mix from PROMEGA. The amplicons were sequenced at the Bioinformatics laboratory at Idaho State University. The sequence results were analyzed with BLAST software, and had a $99 \%$ similarity to several uncultured At. caldus $16 \mathrm{~S}$ clones. 
Statistical analysis

All experiments were carried out in triplicate, and average values and $95 \%$ confidence intervals are reported. A single carboy was used to supply influent medium to three continuous-flow reactors, preventing statistical analysis of influent substrate concentrations.

\section{Results}

Test for heterotrophic growth

When acetate, citrate, 2-ketoglutarate, succinate, or malate were added as a carbon source and sole electron donor, there were no statistically significant differences between effluent cell concentrations and a theoretical washout curve calculated from an unsteady state mass balance that assumed a specific growth rate of zero. The organic acid concentrations were nearly constant between the influent and effluent at steady state. In addition, the dissolved oxygen concentration remained steady between the influent and effluent, at $185 \mu \mathrm{M}$. In comparison, when potassium tetrathionate was added as an electron donor, and ambient carbon dioxide provided the sole carbon source, cultures reached steady state between 360 and 412 h, or $3.60-4.12$ residence times, at $7.40 \times 10^{6} \pm 1.90 \times 10^{6}$ cells ml $^{-1}$, and the effluent dissolved oxygen concentration decreased to $139.4 \pm 1.8 \mu \mathrm{M}$ (data not shown).

\section{Test for mixotrophic growth}

Figure 1a shows changes in the effluent cell concentrations over time when potassium tetrathionate was present with the organic acid. There was little difference in the steady state effluent cell concentrations between cultures containing acetate, citrate, 2-ketoglutarate, succinate, or malate coupled with potassium tetrathionate, and cultures containing only potassium tetrathionate. These effluent cell concentrations ranged between $5.60 \times 10^{6} \pm 9.17 \times 10^{5}$ (citrate) and $7.67 \times 10^{6} \pm 1.40 \times 10^{6}$ cells ml $^{-1}$ (acetate). However, when pyruvate was added, steady state cell concentrations reached $2.07 \times 10^{7} \pm 0.06 \times 10^{7}$ cells ml $^{-1}$.

Figure $1 \mathrm{~b}$ shows that acetate, citrate, 2-ketoglutarate, succinate, and malate concentrations decreased 10-20\% between the influent and effluent at steady state. Conversely, the effluent concentration of pyruvate was below the detection limit $(\sim 2 \mu \mathrm{M})$ at steady state. Figure 2 shows the dissolved oxygen concentration in cultures grown in the presence of pyruvate was also significantly lower than in cultures grown in the presence of other organic acids, $95.4 \pm 3.2 \mu \mathrm{M}$ compared with a low of $136.5 \pm 3.2 \mu \mathrm{M}$ for 2-ketoglutarate and a high of $147.6 \pm 3.3 \mu \mathrm{M}$ for succinate. The effluent dissolved oxygen concentration in the potassium tetrathionate only control was $139.4 \pm 1.8 \mu \mathrm{M}$.

Batch growth with pyruvate as the sole carbon source

Figure 3 shows At. caldus grew mixotrophically in batch cultures when pyruvate provided the sole carbon source and potassium tetrathionate provided an electron donor. When the initial pyruvate concentrations were $5,10,15$, and $20 \mu \mathrm{M}, 54 \pm 6,77 \pm 4,79 \pm 11$, and $82 \pm 15 \%$ of the pyruvate was used anabolically, respectively. Table 1 shows that the decreases in pyruvate concentrations were inversely proportional to the increases in cell concentrations. No cell growth was observed in samples where potassium tetrathionate was withheld.

Toxicity of organic acids in batch cultures

Pyruvate, acetate, citrate, 2-ketoglutarate, succinate, and malate each showed a negligible effect on the specific growth rate at a concentration of $5 \mu \mathrm{M}$. At concentrations at or above $20 \mu \mathrm{M}$, significant inhibitory effects were observed (Fig. 4a). When cells were pre-adapted to pyruvate, the specific growth rate increased by $11 \pm 3,13 \pm 3$, $34 \pm 3,28 \pm 1$, and $7 \pm 1 \%$, at initial concentrations of 5 , $10,20,30$, and $50 \mu \mathrm{M}$, respectively, compared with cells exposed to pyruvate for the first time. When cells were preadapted to acetate, the specific growth rate increased by $4 \pm 2$ and $10 \pm 3 \%$, when the initial concentration was 5 and $10 \mu \mathrm{M}$, respectively, compared to un-adapted cells. No significant increases in specific growth rates were observed after subsequent culturing in the presence of citrate, 2ketoglutarate, succinate, or malate (Fig. 4b).

\section{Discussion}

The presence of heterotrophic or mixotrophic activity in mineral leaching environments has been shown to increase mineral leaching by chemolithotrophic sulfur and ironoxidizers (Marchland and Silverstein 2003; Olson et al. 2003; Gu and Wong 2004, 2007). The work presented here shows that At. caldus can grow mixotrophically using pyruvate as a carbon source and potassium tetrathionate as an electron donor, under aerobic conditions (Figs. 1, 2). Conversely, acetate, citrate, 2-ketoglutarate, succinate, and malate were not used as a significant carbon source.

Because carbon dioxide was available to the cells in the chemostat experiments, separate experiments were designed to determine whether At. caldus is capable of mixotrophic growth on pyruvate in a carbon dioxide limited system. 
Fig. 1 a Effluent cell concentrations of Acidithiobacillus caldus grown in chemostat under mixotrophic conditions. Each respective organic acid supplied a possible electron donor $(50 \mu \mathrm{M})$, in addition to potassium tetrathionate $(10 \mathrm{mM})$, and supplemented ambient carbon dioxide as a potential carbon source. A potassium tetrathionate only control and theoretical washout are presented for comparison. It can be seen that the chemostat comes to steady state between 264 and 336 h. b Influent and steady state effluent concentrations of organic acids corresponding to plot a. Error bars represent $95 \%$ confidence intervals
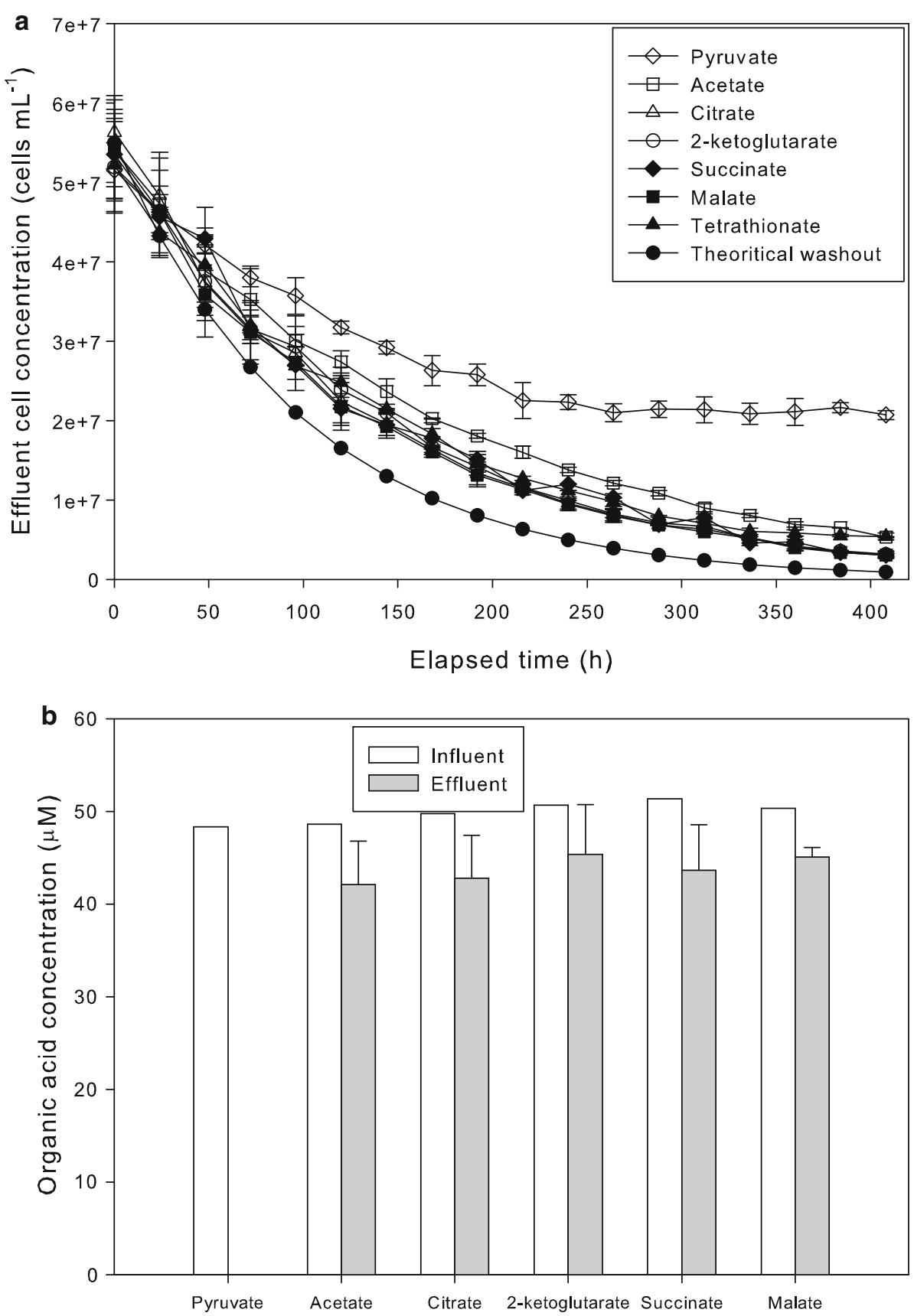

Using media free of dissolved inorganic carbon, we confirmed that At. caldus grew while using pyruvate as the solecarbon source in batch cultures (Fig. 4). Coupled with the inability of At. caldus to grow in the absence of potassium tetrathionate, this further suggests that pyruvate was primarily used for anabolic growth, rather than oxidized solely as an electron donor.

This is not the first report of mixotrophic growth by At. caldus, as Hallberg and Lindstrom (1994) reported that At. caldus strain KU could grow using potassium tetrathionate and either glucose or yeast extract. However, this work is significant because pyruvate has been identified in the spent medium filtrate of At. ferrooxidans (Schnaitman and Lundgren 1965), and is toxic to chemolithotrophic autotrophs at low concentrations under acidic conditions (Aston et al. 2009; Matin 1978). In addition, previous work has shown that removing inhibitory organic acids can significantly increase metal-leaching rates (Marchland and Silverstein 2003; Olson et al. 2003; Gu and Wong 2004, 2007).

Recent studies may provide clues for how At. caldus is able to assimilate pyruvate as a carbon source. Valdes et al. (2008, 2009) used whole-genome shotgun sequencing to assemble a draft genome for At. caldus strain KU (ATCC 
Fig. 2 Dissolved oxygen concentration of the chemostat effluent under mixotrophic conditions. The $x$-axis lists the organic acid supplied with potassium tetrathionate. A potassium tetrathionate only control is shown for comparison. Error bars represent $95 \%$ confidence intervals. The horizontal line indicates the theoretical solubility of oxygen in water under the experimental conditions

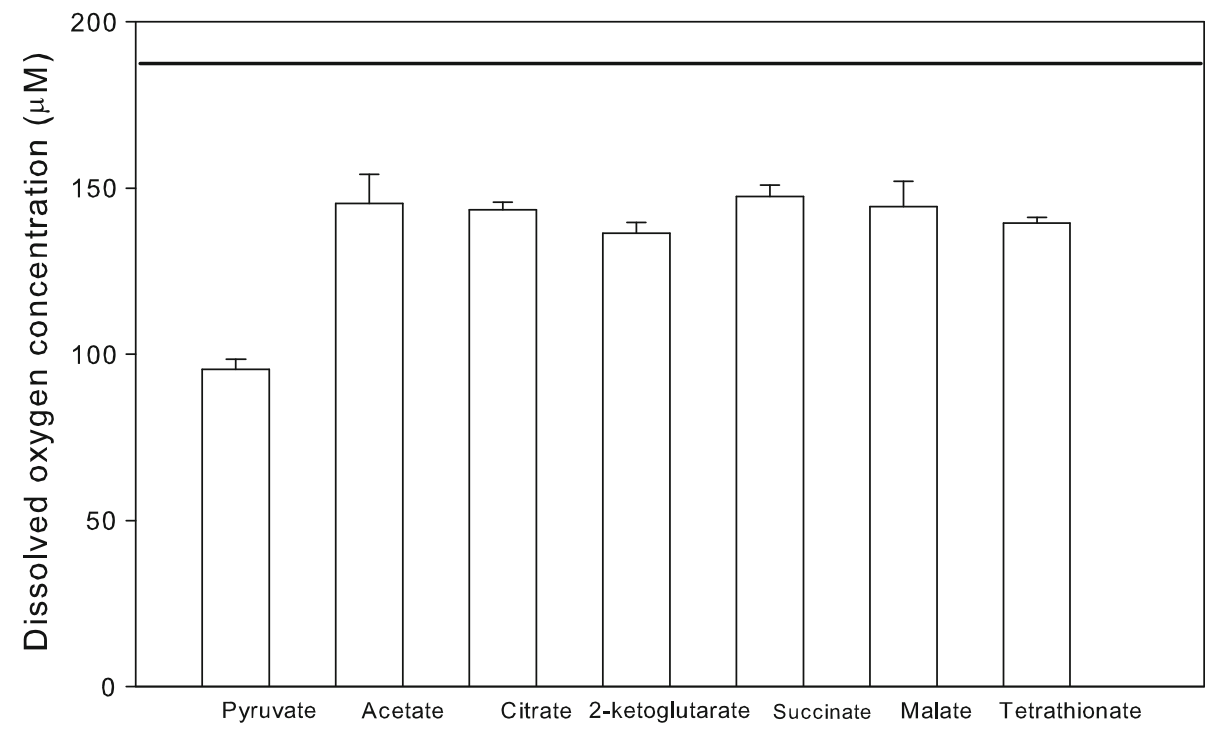

51756) and predict proteins from coding sequences. Sequences coding for pyruvate dehydrogenase and phosphoenolpyruvate synthase were identified. Pyruvate dehydrogenase catalyzes the oxidation of pyruvate to carbon dioxide and acetyl-CoA. Carbon dioxide could then be fixed via the Calvin cycle, and acetyl-CoA could be used as a precursor for lipid synthesis, for which the necessary genes were also identified (Valdes et al. 2009). This mechanism would be similar to the anabolic oxidation of formate by At. thiooxidans (Pronk et al. 1991), where formate was oxidized to carbon dioxide, which could then be fixed for anabolic growth. In such a mechanism, the reducing equivalents required to fix carbon dioxide would prevent the oxidized organic acid from being used as the sole electron donor, therefore necessitating the presence of a reduced sulfur compound for growth. In addition, phosphoenolpyruvate synthase reduces pyruvate to phosphoenolpyruvate. Valdes et al. (2009) predicted the necessary enzymes were present to fix phosphoenolpyruvate into fivecarbon sugars important for anabolic growth using gluconeogenesis and the pentose phosphate pathway. In this study, pyruvate in particular showed a significant increase in specific growth rates following adaptation (Fig. 4). This suggests that the expression of enzymes that may facilitate pyruvate metabolism, such as those discussed above, or proteins that aid in resisting organic acid toxicity, increased with prior exposure.

Valdes et al. (2008) also identified the presence of an incomplete TCA cycle (lacking 2-ketoglutarate dehydrogenase). However, the present study indicates that At. caldus does not assimilate external organic acids used in the TCA cycle (citrate, 2-ketoglutarate, succinate, and malate), suggesting that it may lack the required transport mechanisms, or can only use concentrations of these acids lower than those used in this study.
It is interesting that under mixotrophic conditions, the effluent cell concentrations in chemostat cultures containing acetate, 2-ketoglutarate, succinate, or malate did not differ statistically from cultures containing only potassium tetrathionate given that they were not used as a carbon source and are toxic at the concentrations measured in the effluent (Figs. 1, 4). The dilution rate used in these chemostat studies $\left(0.01 \mathrm{~h}^{-1}\right)$ was lower than the specific growth rates observed in batch cultures that contained acetate, citrate, 2-ketoglutarate, succinate, or malate $\left(0.016-0.023 \mathrm{~h}^{-1}\right.$ at $\left.50 \mu \mathrm{M}\right)$. There have been several studies that reported a correlation between bacterial growth phase and the toxicity of a given inhibitor (including but not limited to: Richard and Foster 2003; Yilmaz 2003). By fixing the specific growth rate in the chemostat at $0.01 \mathrm{~h}^{-1}$, the toxic effect of the organic acids may be reduced, or masked by the already low specific growth rate. A previous study with Thiobacillus acidophilus reported a similar effect, where, although no growth was observed in batch cultures containing pyruvate, cells grew and oxidized pyruvate in a chemostat culture (Pronk et al. 1989).

We did not observe At. caldus growth when organic acids were supplied as the sole electron donor in either chemostat or batch cultures. Therefore, it is likely that the slight decrease in the concentration of organic acids between the influent and the effluent at steady state (data not shown) was due to chemiosmosis (Ingledew and Poole 1982). It is also possible that a portion of this decrease in organic acids was due to anabolic maintenance, but because the dissolved oxygen concentration remained nearly constant, this would have been an energetically limited process. These results were not surprising, as no acidithiobacilli have been observed to grow using organic acids as a sole energy source. 
Fig. 3 a Growth of Acidithiobacillus caldus in batch cultures using pyruvate as the sole carbon source and b initial and final pyruvate concentrations when provided as the sole carbon source in batch cultures. Potassium tetrathionate was present at a concentration of $10 \mathrm{mM}$. Error bars represent $95 \%$ confidence intervals
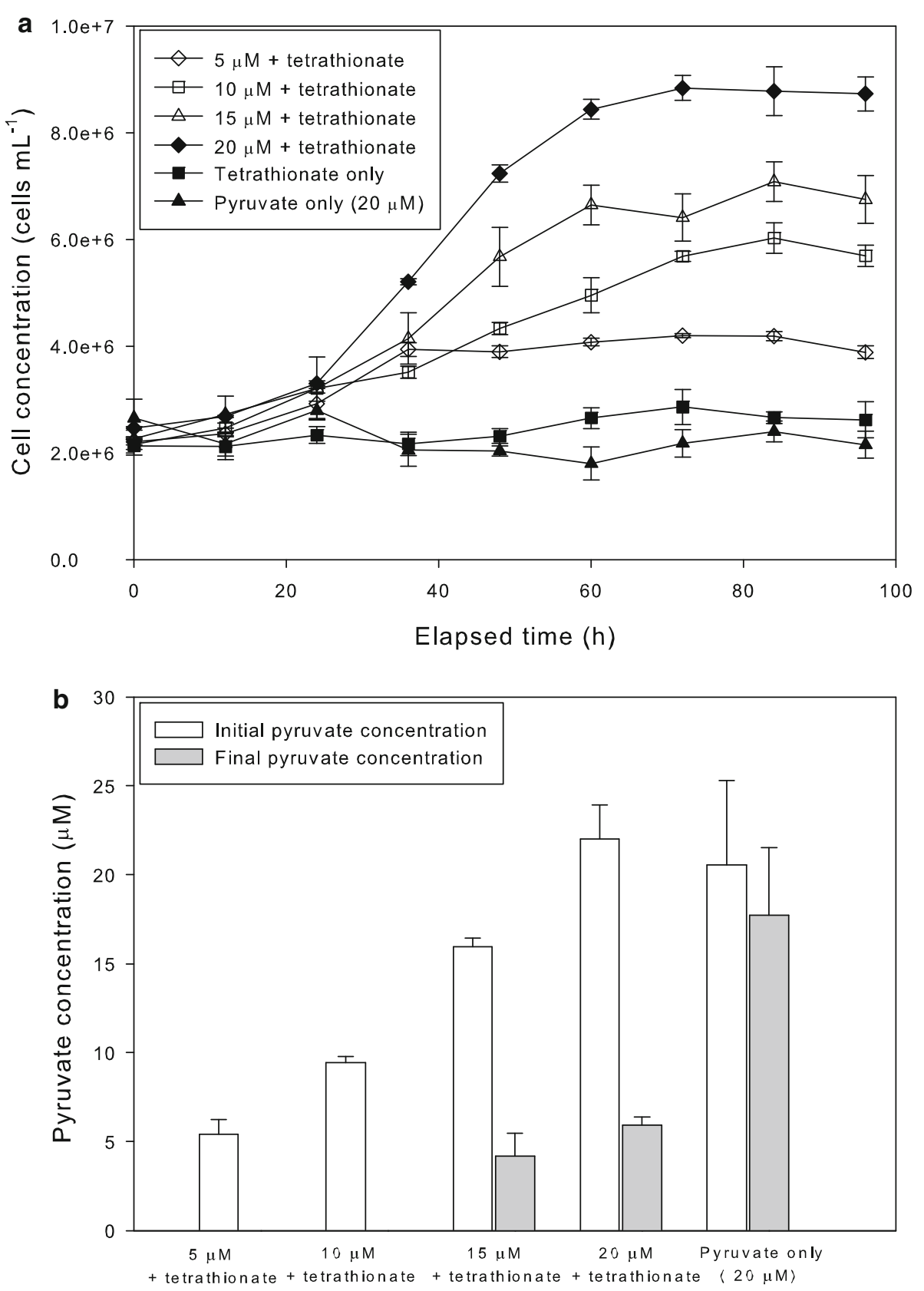

Table 1 Percent of pyruvate consumed and converted to biomass by Acidithiobacillus caldus cells, in carbon dioxide free media, at initial concentrations of $5,10,15$, or $20 \mu \mathrm{M}$

\begin{tabular}{lll}
\hline $\begin{array}{l}\text { Pyruvate } \\
\text { concentration }(\mu \mathrm{M})\end{array}$ & $\begin{array}{l}\text { Pyruvate } \\
\text { uptake }(\%)\end{array}$ & $\begin{array}{l}\text { Pyruvate converted } \\
\text { to biomass }(\%)\end{array}$ \\
\hline 5 & $100 \pm 0$ & $65 \pm 8$ \\
10 & $100 \pm 0$ & $77 \pm 4$ \\
15 & $74 \pm 7$ & $79 \pm 11$ \\
20 & $73 \pm 4$ & $82 \pm 15$ \\
\hline
\end{tabular}

Potassium tetrathionate was added to a concentration of $10 \mathrm{mM}$ to provide an inorganic electron donor

\section{Summary and conclusions}

The work presented here shows that At. caldus can use pyruvate for anabolic growth under mixotrophic conditions. In addition, prior exposure to pyruvate significantly increased the specific growth rate of At. caldus when pyruvate was added to batch cultures. However, At. caldus could not grow when pyruvate was the sole electron donor, nor could it use acetate, citrate, 2-ketoglutarate, succinate, or malate as energy or carbon sources to a significant extent at the concentrations used in this study. This work is an 
Fig. 4 Effect of pyruvate, acetate, citrate, 2-ketoglutarate, succinate, and malate on the specific growth rate of Acidithiobacillus caldus during batch growth conditions after a a single transfer from identical conditions and $\mathbf{b}$ four sequential transfers between identical conditions. $\mu$ represents the specific growth rate observed without prior exposure to the respective organic acid, and $\mu_{o}$ represents the specific growth rate observed in cultures with prior exposure to the respective organic acid. Potassium tetrathionate was present at a concentration of $10 \mathrm{mM}$. Error bars represent $95 \%$ confidence intervals
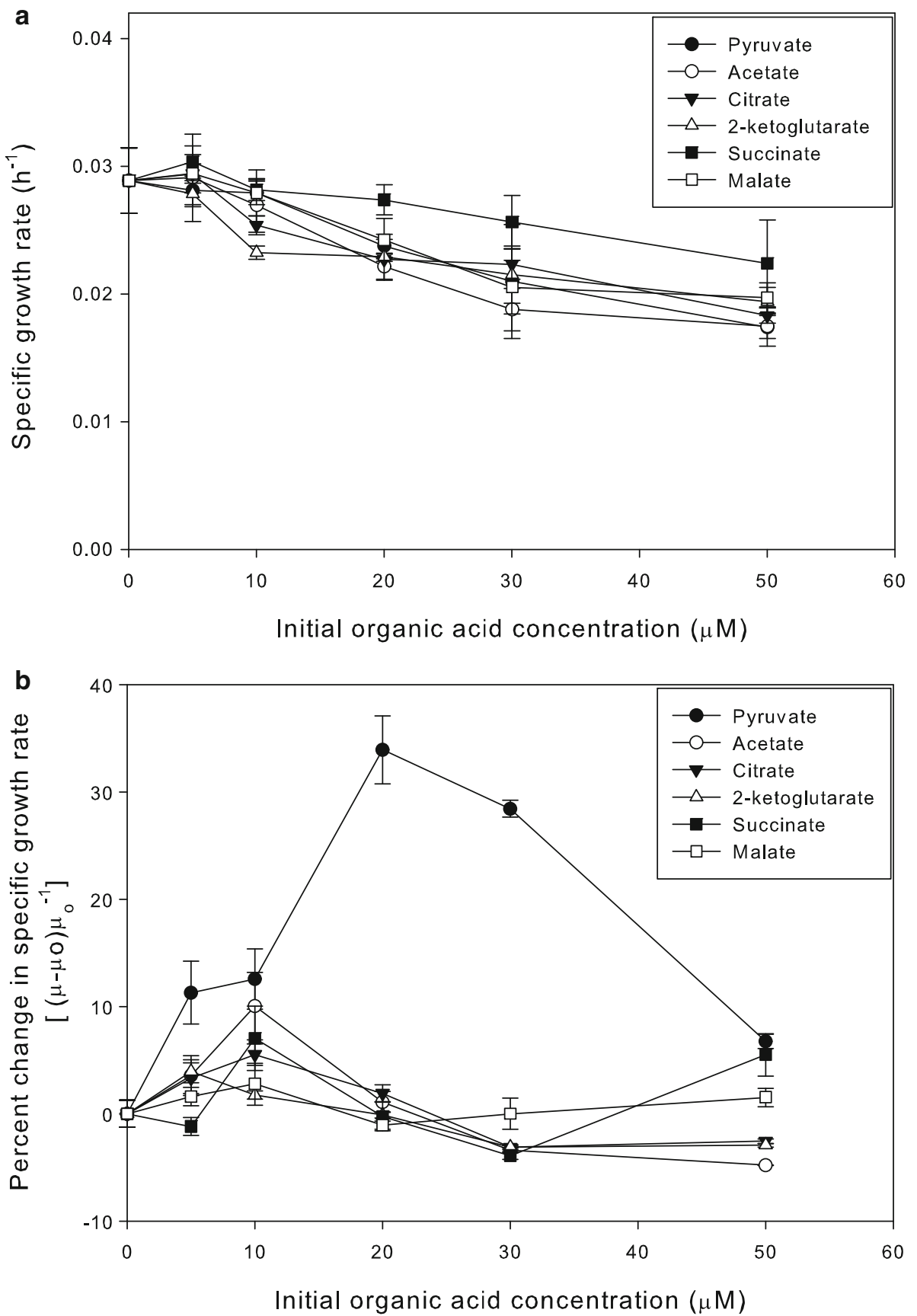

important contribution towards understanding the metabolic capabilities of At. caldus, and its role in microbial communities and industrial and environmental applications.

Acknowledgments This work was supported in part through the Idaho National Laboratory Directed Research and Development program under Department of Energy Idaho Operations Office Contract DE-AC07-05ID14517. The authors also thank the Montana Experimental Program to Stimulate Competitive Research and the National Science Foundation Integrated Graduate Education Research Training program for financial support (grant \# DGE-0654336), as well as the Department of Chemical and Biological Engineering and Center for Biofilm Engineering at Montana State University.

\section{References}

Aston JA, Apel WA, Lee BD, Peyton BM (2009) Toxicity of select organic acids to the slightly thermophilic acidophile Acidithiobacillus caldus. Environ Toxicol Chem 28:279-286

Borischewski RM (1967) Keto acids as growth-limiting factors in autotrophic growth of Thiobacillus thiooxidans. J Bacteriol 93:597-599

Burckhard SR, Schwab AP, Banks MK (1995) The effects of organic acids on the leaching of heavy metals from mine tailings. J Hazard Mat 41:135-145

Dopson M, Lindstrom EB (1999) Potential role of Thiobacillus caldus in arsenopyrite bioleaching. Appl Environ Microbiol 65:36-40 
Dopson M, Lindstrom EB, Hallberg KB (2002) ATP generation during reduced inorganic sulfur compound oxidation by Acidithiobacillus caldus is exclusively due to electron transport phosphorylation. Extremophiles 6:123-129

Edwards KJ, Bond PL, Banfield JF (2000) Characteristics of attachment and growth of Thiobacillus caldus on sulphide minerals: a chemotactic response to sulphur minerals? Environ Microbiol 2:324-332

Fu B, Zhou H, Zhang R, Qiu G (2008) Bioleaching of chalcopyrite by pure and mixed cultures of Acidithiobacillus spp. and Leptospirillum ferriphilum. Int $\mathrm{J}$ Biodeterior Biodegradation 62: $109-115$

Gu XY, Wong JWC (2004) Identification of inhibitory substances affecting bioleaching of heavy metals from anaerobically digested sewage sludge. Eniviron Sci Technol 38:2934-2939

Gu XY, Wong JWC (2007) Degradation of inhibitory substances by heterotrophic microorganisms during bioleaching of heavy metals from anaerobically digested sewage sludge. Chemosphere 69:311-318

Hallberg KB, Lindstrom EB (1994) Characterization of Thiobacillus caldus sp. Nov., a moderately thermophilic acidophile. Microbiology 140:3451-3456

Hallberg KB, Lindstrom EB (1996) Multiple serotypes of the moderate thermophile Thiobacillus caldus, a limitation of immunological assays for biomining microorganisms. Appl Environ Microbiol 62:4243-4246

Ingledew WJ, Poole RK (1982) Thiobacillus ferrooxidans: the bioenergetics of an acidophilic chemolithotroph. Biochem Biophys Acta 683:89-117

Marchland EA, Silverstein J (2003) The role of enhanced heterotrophic bacterial growth on iron oxidation by Acidithiobacillus ferrooxidans. Geomicrobiol J 20:231-244

Matin A (1978) Organic nutrition of chemolithotrophic bacteria. Annu Rev Microbiol 32:433-468

McGuire MM, Edwards KJ, Banfield JF, Hamers RJ (2001) Kinetics, surface chemistry, and structural evolution of microbially mediated sulfide mineral dissolution. Geochem Cosmochim Acta 65:1243-1258

Okibe N, Gericke M, Hallberg KB, Johnson DB (2003) Enumeration and characterization of acidophilic microorganisms isolated for a pilot plant stirred-tank bioleaching operation. Appl Environ Microbiol 69:1936-1943
Olson GJ, Brierley JA, Brierley CL (2003) Bioleaching review. Part B: progress in bioleaching: applications of microbial processes by the mineral industries. Appl Microbiol Biotechnol 63:249257

Pronk JT, Meesters PJW, van Dijken JP, Bos P, Kuenen JG (1989) Heterotrophic growth of Thiobacillus acidophilus in batch and chemostat cultures. Microbiology 153:392-398

Pronk JT, Mejer WM, Hazeu W, van Dijken JP, Bos P, Kuenen JG (1991) Growth of Thiobacillus thiooxidans on formic acid. Appl Environ Microbiol 57:2057-2062

Rawlings DE (2002) Heavy metal mining using microbes. Annu Rev Microbiol 56:65-91

Richard HT, Foster JW (2003) Acid resistance in Escherichia coli. Adv Appl Microbiol 52:167-184

Schnaitman C, Lundgren D (1965) Organic compounds in the spent medium of Ferrobacillus ferrooxidans. Can J Microbiol 1:23-27

Temple KL, Colmer AR (1951) The autotrophic oxidation of iron by an new bacterium, Thiobacillus ferrooxidans. J Bacteriol 62:605-611

Tuttle JH, Dugan PR, Apel WA (1977) Leakage of cellular material from Thiobacillus ferrooxidans in the presence of organic acids. Appl Environ Microbiol 33:459-469

Valdes J, Pedroso I, Quatrini R, Holmes DS (2008) Comparative genome analysis of Acidithiobacillus ferrooxidans, A. thiooxidans and A. caldus: insights into their metabolism and ecophysiology. Hydrometallurgy 94:180-184

Valdes J, Quatrini R, Hallberg K, Dopson M, Valenzuela PDT, Holmes DS (2009) Draft genome sequence of the extremely acidophilic bacterium Acidithiobacillus caldus ATCC 51756 reveals metabolic versatility in the genus Acidithiobacillus. J Bact 191:5877-5878

Waksman SA, Joffe JS (1922) Microorganisms concerned in the oxidation of sulfur in the soil II. Thiobacillus thiooxidans, a new sulfuroxidizing organism isolated from the soil. J Bacteriol 7:239-256

Yilmaz EI (2003) Metal tolerance and biosorption capacity of Bacillus circulans strain EB1. Res Microbiol 154:409-415

Zhou QG, Bo F, Bo ZH, Xi L, Jian G, Fei LF, Hau CH (2007) Isolation of a strain of Acidithiobacillus caldus and its role in bioleaching of chalcopyrite. World J Microbiol Biotechnol 23:1217-1225 